Gmelins Handbuch der anorganischen Chemie Achte Auflage. Herausgegeben von der Deutschen Chemischen Gesellschaft. System-Nummer 35: Aluminium. Teil A, Lief. 2. Pp. 285-450. 26 gold marks. Teil B : Die Verbindungen des Aluminiums, Lief. 2. Pp. 309-613. 49 gold marks. (Berlin : Verlag Chemie G.m.b.H., 1934.)

THE well-known property possessed by aluminium of coating its surface with an invisible, firmly adhering and continuous skin of oxide has rendered the systematic investigation of its electrochemical be. haviour extraordinarily difficult, while at the same time it has had most important practical results in the industrial application of the metal. Thus the properties of pure aluminium may be very different from those of the commercial metal. Accordingly, about one quarter of Part A, Section 2, of the volumes on aluminium is occupied with a discussion of electrochemical measurements. The remainder deals with the chemical action on aluminium of non-metals, water, acids and alkalis, including organic reagents.

Part B, Section 2, deals with a large variety of compounds of aluminium, including the silicates and the changes which kaolin undergoes when subjected to heat, natural and synthetic zeolites, the various alums and ultramarines. Historical accounts of the uses of alum and ultramarine are given. The latter has been in use as a dye since the eleventh century. Recent work upon its constitution has shown that in all ultramarines the ratio $\mathrm{SiO}_{2}: \mathrm{Al}_{2} \mathrm{O}_{3}$ remains practically constant in the silicate frame, and the colour depends not only upon the sulphur which is present but also upon the alkali. The latter can be partly or almost completely extracted from blue ultramarine by means of chlorine and certain organic solvents. The colour is thereby destroyed, but it can be restored by the addition of alkali. When chlorine was used it was found that the colourless product retained the original crysta] lattice structure.

\section{Chinese Art}

Edited by Leigh Ashton. Introduction, by Laurence Binyon; Painting and Calligraphy, by Laurence Binyon; Sculpture and Lacquer, by Leigh Ashton; The Potter's Art, by R. L. Hobson; Bronzes, by A. J. Koop ; Jades, by Una Pope-Hennessy ; Textiles, by Leigh Ashton. Pp. xvi $+111+23$ plates. (London : Kegan Paul and Co., Ltd., 1935.) Paper, 2s. 6d. net; cloth, 3s. 6d. net.

TuIs little book, which has been prepared in anticipation of the exhibition of Chinese art being held at the Royal Academy, Burlington House, does not call for extended comment, excellent though it is. It is intended for the uninitiated, and has been written by experts in the respective fields with which each deals, as indicated in the title-page. The essays are short, but have been skilfully adapted to their purpose of giving the Western visitor to the exhibition an idea of the Chinese artistic and technical achievement, as well as of the mentality and range of imagination of the Chinese artist. The dynastic and chronological relations of the exhibits - of the first importance in the appreciation of Chinese culture-receive due attention. The book is liberally illustrated.

\section{Modern Production among Backward Peoples}

By Dr. I. C. Greaves. (London School of Economics and Political Science: Studies in Economics and Commerce, No. 5.) Pp. 229. (London: George Allen and Unwin, Ltd., 1935.) 10s. 6d. net.

Dr. Greaves has broken new ground in her study of the economic activities and organisation found among backward peoples as the result of the introduction of European methods of exploitation of their resources. The data she has collected, as well as her conclusions, are of interest to economist, anthropologist and administrator alike. For the anthropologist they form an object lesson in culture contact, available equally for academic use and practical application ; for the administrator, a message of guidance and warning; and for the economist, in the author's attitude to cultural differences, a new orientation in the assessment of comparative values.

Dr. Greaves passes under review the function of the State in administering backward territory in relation to imports, exports and the investments of capital from outside sources. She shows how, still keeping this triple aim in view, policy has changed direction from promoting the interests of the European, whether settler or ruling people, to a substantial, if not exclusive, support of indigenous activity. How far this is general depends upon local conditions, and all stages of development are to be found, going indeed so far in one direction as the complete segregation which is the ideal, not, however, realised in practice, in South Africa.

A wide variety of economic problems has been brought under review by the author, and her book is a store of information, as well as a well thought out and impartial survey of conditions and tendencies.

\section{Low Temperature Physics}

By Dr. L. C. Jackson. (Methuen's Monographs on Physical Subjects.) Pp. vii +122 . (London : Methuen and Co., Ltd., 1934.) 3s. net.

UNTrL quite recently, the development of low temperature research has been carried on almost entirely abroad, and although the book has had to be restricted to a few sections of especial interest and, in particular, dealing largely with the range of temperature $1^{\circ}-20^{\circ}$ abs., a remarkably comprehensive survey is compressed into the six chapters on the production of low temperatures, their measurement, liquid and solid helium, specific heats, electrical conductivity and magnetism. The latest work on the region below $1^{\circ}$ abs. is notable, and, in view of the interest and importance of electrical and magnetic phenomena at low temperatures in connexion with atomic and lattice structure, the last two chapter. give a valuable summary of recent experimental and theoretical advances.

Although the book is mainly concerned with the description of experimental technique, given in many cases with illustrative curves and numerical data for a large number of substances, the mathematical theory and expression of the various aspects of the subject are not neglected. References to more than a hundred original papers are provided. N. M. B. 